UNIVERSIDADE ESTADUAL DE FEIRA DE SANTANA

Autorizada pelo Decreto Federal $n^{\circ} 77.496$ de 27/04/76

Recredenciamento pelo Decreto $n^{\circ} 17.228$ de $25 / 11 / 2016$

PPPG

PRÓ-REITORIA DE PESQUISA E PÓS-GRADUAÇÃO

COORDENAÇÃO DE INICIAÇÃO CIENTÍFICA

XXIII SEMINÁRIO DE INICIACCÃO CIENTÍFICA DA UEFS

SEMANA NACIONAL DE CIENTÍFICA E TECNOLÓGICA - 2019

\title{
PROFESSORES DO ENSINO SUPERIOR: CONTRIBUIÇÕES DA PESQUISA- AÇÃO COLABORATIVA PARA A COMPREENSÃO DA PROFISSIONALIDADE DOCENTE
}

\author{
Laura da Cunha Ferreira'; Amali de Angelis Mussi ${ }^{2}$ \\ 1. Bolsista PIBIC/CNPq, Graduando em Letras Vernáculas, Universidade Estadual de Feira de Santana, e-mail: \\ lauracunha_52@hotmail.com \\ 2. Orientadora, Departamento de Educação, Universidade Estadual de Feira de Santana, e-mail: \\ amalimussi@hotmail.com
}

PALAVRAS-CHAVE: Professores do Ensino Superior; Profissionalidade Docente; Pedagogia universitária.

\section{INTRODUÇÃO}

Para buscar compreender como se constitui a profissionalidade docente e quais os saberes que caracterizam a especificidade da atividade profissional, foram realizados estudos discutindo as condições em que os docentes exercem sua profissão no ensino superior e que repercussões o contexto de trabalho refletem na sua prática. A construção teórica do conceito de profissionalidade está em formação por ser muito complexa (GORZONI; DAVIS, 2016), entretanto alguns teóricos atentaram se a essa temática que tem uma importante relevância no contexto social e histórico na formação e prática de professores.

As pesquisas sobre profissionalidade docente têm foco nos aspectos relacionados à atividade profissional e aos processos de formação e desenvolvimento profissional do professor (ALVES; ANDRÉ, 2013; AMBROSETTI; ALMEIDA,2007; ROLDÃO, 2005; TARDIF, 2002; NÓVOA, 1992; entre outros. Por meio de diferentes linhas de análise, essas investigações concebem o professor como um profissional que deve ser capaz de refletir e resolver questões da sua prática profissional por meio da mobilização de saberes e conhecimentos específicos da docência.

Com base na literatura investigada e nos relatos dos professores, esse trabalho buscou apreender os sentidos e significados que os docentes atribuem como efeitos do contexto de trabalho para a constituição de sua profissionalidade.

\section{MATERIAL E MÉTODOS OU METODOLOGIA (ou equivalente)}

A pesquisa-ação colaborativa foi a metodologia escolhida "por incorporar a ação como sua dimensão constitutiva" (MIRANDA e RESENDE, 2006, p. 511). A pesquisa colaborativa faz com que os sujeitos estejam em pesquisa, ou seja, reflitam sobre os problemas e as dificuldades encontradas na prática de ensino, a fim de superálas. Trata-se de um trabalho reflexivo sobre as atividades de sua vida social e profissional, sobre suas práticas e sua experiência.

Para desenvolver a pesquisa realizamos a aplicação de questionário, optamos por esse recurso para obter dados necessários à produção desse projeto de forma didática e mais objetiva, sendo aplicadas questões referentes aos caracterizadores da profissionalidade descritos por Roldão (2005). Com o objetivo de compreender, a partir 
dos relatos de professores do ensino superior, os sentidos e significados que atribuem como efeitos do contexto de trabalho para a constituição de sua profissionalidade, as questões que nortearam essa pesquisa foram: a) Saber quais fatores contribuíram para se tornar o professor que é hoje, b) De que modo como sente os efeitos do contexto de trabalho na constituição da profissionalidade, c) Quais as contribuições da pesquisaação para o desenvolvimento da sua profissionalidade, tanto como participante da pesquisa, quanto como pesquisador.

\section{resultados) \\ RESULTADOS E/OU DISCUSSÃO (ou Análise e discussão dos}

A prática de uma profissão é desenvolvida a partir de um conjunto de atributos que caracterizam um bom desempenho da atividade desenvolvida. Roldão (2005) tem centrado seus estudos no aprofundamento de questões ligadas à profissionalidade docente. Para a autora, a profissionalidade é um processo progressivo de construção profissional que segue ao longo de toda vida ativa do professor.

No cenário da docência, a profissionalidade se desenvolve com o exercício principal do professor; o ensino. Para isso, é importante que o professor domine os conteúdos estudados, tenha autonomia na sua profissão, habilidades e saberes específicos de sua função a fim de que proporcione uma boa aprendizagem dos alunos, é essencial que o professor compreenda como o outro aprende, conheça e desenvolva práticas pedagógicas bem fundamentadas e faça parte de um grupo de socialização entre os docentes para estar sempre refletindo e inovando a práxis educativa.

Contudo, ainda que o docente desenvolva sua atividade baseada nos aspectos que compõe a profissionalidade docente, não é possível assegurar integralmente o exercício da docência. As questões do contexto de trabalho são condicionantes de destaque nesse ofício, elas perpassam por questões estruturais do ambiente de trabalho, organização de horários, alta demanda de atividades que o professor do ensino superior deve dar conta e assim por diante. Compreender a profissionalidade docente é ter a consciência de que as práticas de ensino não dizem respeito a um único saber especializado e que há vários aspectos constituintes que fazem dessa profissão uma atividade de caráter polissêmico que exige conhecimento e competências em vários campos, além de um exercício constante de readaptação frente aos acontecimentos sociais e históricos.

\section{CONSIDERAÇÕES FINAIS (ou Conclusão)}

Levando em conta o que foi observado, os componentes da profissionalidade perpassam por questões sociais, políticas, profissionais, pessoais, históricas e pedagógicas. O trabalho docente se desenvolve com apoio em diferentes campos do conhecimento, como foi dito: os saberes específicos essenciais à sua prática, a autonomia profissional, o desenvolvimento de um trabalho coletivo em paralelo com as competências e habilidades individual fundamentais para construir sua independência profissional, capacidade de lidar com questões sócio-políticas, convivência em grupo para realizar atividades coletivas e compartilhar conhecimentos a fim de que possa afirma-se individualmente e também fortalecer seu valor social.

Fica evidente a relevância desenvolver práticas exclusivas do seu papel de educador para corporificar a profissionalidade, mas também, é muito importante saber que a profissionalidade, embora seja fundamental, não assegura a efetiva qualidade da docência, pois ela precisa de uma condição que é política: contexto de 
trabalho, valorização do professor, uma boa gestão, ambiente estruturado para aulas e pesquisas, alunos motivados a aprender e assim por diante.

É irrefutável o grande desafio que os professores enfrentam para desempenhar sua função, pois é na atuação que eles põem em práticas os conhecimentos específicos de seu papel de educador. As instituições de ensino precisam oferecer mais programas que possibilitem o aperfeiçoamento e ressignificação da prática, isto é: oferecer condições essenciais ao desempenho da tarefa docente, ter uma boa gestão, equalizar o tempo de trabalho a fim de que haja promoção de espaços para socialização dos docentes, como bem fundamenta Mussi e Almeida (2015) “(...) defender uma formação profissional pautada por um objeto elaborado, vivido, (re) construído por toda equipe de profissionais que nele atuam e que dele fazem uso".

Como conclusão desses estudos, na visão dos docentes, a pesquisa-ação se coloca como um elemento fundante por meio da qual a autonomia passa a constituir possibilidades de entendimento e inovação da docência que cada um realiza. O componente de maior destaque que resultou dos efeitos do contexto de trabalho na constituição da profissionalidade docente, foi a socialização da prática, todos os professores relataram a importância dessa atividade como forma de estar sempre melhorando o exercício docente, questionar e analisar a realidade é um trabalho que contribui muito na formação do professor e na melhoria da qualidade no ensino superior.

\section{REFERÊNCIAS}

ALVES, C. S.; ANDRÉ, Marli E. D. A. A constituição da profissionalidade docente: os efeitos docampo de tensão do contexto escolar sobre os professores. In: ANPED. $36^{\mathrm{a}}$ Reunião Anual da ANPED, 2013, Goiânia, GO. Acesso em: 02/8/2014.

AMBROSETI, N.; ALMEIDA, P. C. A. A constituição da profissionalidade docente: tornar-se professora de educação infantil. In: ANPED. 30ª Reunião Anual da ANPED, 2007, Caxambú. Acesso em: 15/5/2014.

BARDIN, Laurence. Análise de conteúdo. Lisboa: Edições 70, 1997.

DAY, C. Committed for life? Variations in teachers ${ }^{\text {ee }}$ work, lives and effertiveness. Journal of Educational Change, v. 9, n. 3, sep. 2008. p. 243-260. Disponível em http://www.springerlink.com.w10057.dotlib.com.br/content/92966j241675k5x2/fulltext. pdf. Acesso em 27 fev 2018.

DUBAR, Claude. A socialização: a construção das identidades sociais e profissionais. Porto: Porto Editora, 1997.

GATTI, Bernardete. Os Professores e suas identidades: o desenvolvimento da heterogenidade. São Paulo: Cadernos de Pesquisa, nº 98, p. 85-90, ago, 1996.

GATTI, B. A.; BARRETO, E. S. (coord.) Professores do Brasil: impasses e desafios. Brasilia: UNESCO, 2009.

LENOIR,Yves; LAFOREST, Mario (Dir). La bureaucratisation de la recherche en education et en sciences sociales. Constats, impacts et conséquences. Revue fraçaise de pédagogie, 1998, v. 123, n.123, pp.176-178.

LOUIS, Roland. Inovação pedagógica no ensino superior. In: CUNHA, Maria Isabel da; SOARES, Sandra Regina; RIBEIRO, Marinalva Lopes (orgs.). Docência universitária: profissionalização e práticas educativas. Feira de Santana: UEFS Editora, 2009. 
MARCELO GARCÍA, Carlos. Formação de Professores: para uma mudança educativa. Porto: Porto Editora, 1999.

MASETTO, Marcos T.. Cadernos de pedagogia universitária: Docência no ensino superior voltada para a aprendizagem faz a diferença. 12. ed. São Paulo: Puc - São Paulo/mackenzie, 2010. $36 \mathrm{f}$.

MIRANDA, M. G.; RESENDE, A. C. A. . Sobre a pesquisa-ação na educação e as armadilhas do praticismo. Revista Brasileira de Educação, v. 11, p. 511-518, 2006.

NÓVOA, António. A formação de professores e a profissão docente. In: NÓVOA. António (org.). Os professores e a sua formação. Lisboa: Publicações Dom Quixote, 1992.

ROLDÃO, Maria do Céu. Profissionalidade docente em análise: especificidades dos ensinos superior e não superior. Nuances: Estudos sobre educação. Ano XI, v. 12, n. 13, jan/dez, 2005, p. $105-126$.

SOBRINHO, José Dias. Professor universitário: contextos, problemas e oportunidades. In CUNHA, Maria Isabel; SOARES, Sandra Regina; RIBEIRO, Marinalva Lopes (Orgs.). Docência Universitária: profissionalização e práticas educativas. Feira de Santana: UEFS Editora, 2009. p. 15-31.

TARDIF, Maurice. Saberes docentes e formação profissional. Petrópolis, RJ: Vozes, 2002. $325 \mathrm{p}$.

TARDIF, M. e LESSARD, C. O trabalho docente: elementos para uma teoria da docência como profissão. $3^{\text {a }}$ ed. Petrópolis/RJ: Vozes Ed., 2007.

ZABALZA, M.A. O ensino universitário: seu cenário e seus protagonistas. Porto Alegre: Artmed, 2004.

MUSSI, Amali de Angelis; ALMEIDA, Elisa Carneiro Santos (Comp.). Profissionalidade docente: uma análise a partir das relações entre os professores e o contexto de trabalho no ensino superior. 2015. Disponível em: <http://37reuniao.anped.org.br/wpcontent/uploads/2015/02/Trabalho-GT08-4324.pdf>. Acesso em: 21 fev. 2019.

BAZZO, Vera Lucia. Profissionalidade docente na Educação Superior Mestres ou Cientistas. $2010 . \quad$ Disponível em: $<$ http://www.ergonomia.ufpr.br/Metodologia/Profissionalidade\%20Docente\%20na\%20Ed\%20S up\%20Mestres\%20ou\%20Cientistas.pdf>. Acesso em: 21 fev. 2019.

RIBEIRO, Marinalva Lopes; MOREIRA, Jefferson da Silva. A busca da profissionalidade da docência no ensino superior. In: Revista educação e emancipação, São Luís, v.9, n.2. jul/dez. 2016.

ROLDÃO, Maria do Céu. Função docente: natureza e construção do conhecimento profissional. 2007. Disponível em: <http://www.scielo.br/pdf/rbedu/v12n34/a08v1234.pdf>. Acesso em: 23 out. 2018. 